\title{
Influence of Nanocomposite Materials for Next Generation Nano Lithography
}

\author{
Scott Lewis and Lucio Piccirillo \\ The University of Manchester, \\ United Kingdom
}

\section{Introduction}

The trend of Moore's law has been maintained using the current technology of the ultra large scale integration which produces circuits of sub $100 \mathrm{~nm}$ (Gonsalves et al., 2001). This has been made possible by sub 100nm lithography, by the design of next generation resists operating at extreme ultra violet wavelengths. However, it is well known that electron beam lithography can achieve similar dimensions using positive tone e-beam resists such as PolyMethylMethAcrylate (PMMA), Polybutene - 1 - Sulfone (PBS) and ZEP520 (Dean et al., 1994) resists. Upon exposure, the molecular weight of the polymer chains, are reduced by the chain scission process. This increases the solubility of the polymer in organic solvents. Figure 1 illustrates the chain scission process with a resist called PMMA. The chain scission process occurs when the radiolysis of the main chain carbon to carbonyl bond is initiated by the electron. The main chain is cleaved and produces unstable products.<smiles>C=C(C)CCCCCCCCCCC(C)(CC(C)(CC(C)(CC)C(=O)OC)C(=O)OC)C(=O)OC</smiles>

Fig. 1. E-beam chain scission process with PMMA e-beam resist.

Therefore, the dissolution rate is increased in an organic developer like Methyl - IsoButyl Ketone (MIBK): IsoPropAnol (IPA) (1:3 ratio) as the main - chain scissions reduces molecular weight of the PMMA. Unfortunately, there is a limit to the negative scaling factor, called the proximity effect (T. Ishii et al 1997). Therefore, it is essential to optimize these resists to perform with a higher sensitivity for high throughput and a higher contrast to achieve sub $100 \mathrm{~nm}$ resolution.

As a figure of merit, the smallest feature size possible with PMMA is approximately 100nm when the resist thickness is approximately $400 \mathrm{~nm}$. Hence, the aspect ratio is $4: 1$. This is due to the fact that a minority of the incident electrons when penetrating the surface of the PMMA resist undergo small angle forward scattering while the majority of them participate in large angle scattering events that contribute to backscattering. Therefore, this leads to 
additional exposure in the bulk resist (the proximity effect), outside of the intended 'write volume'. The bulk of the resist is exposed by primary electrons. As their range in the resist is only a few nanometers their contributions to the proximity effect are negligible. However, secondary electrons (SE) may be generated from the primary electrons and may have energies of the order of 1 to $5 \mathrm{KeV}$. This is significant, because these fast electrons can have a range of a few tenths of a micron, thus contributing to the proximity effect. This has been illustrated by the Monte Carlo simulation of electron trajectories in figure 2. Figure 2 illustrates the proximity effect which is indicated by the red line, it can be seen that the trajectories of the secondary electrons can interfere with the structure adjacent to it, thus to achieve ever decreasing features the overall resist thickness must be decreased to compensate for this.

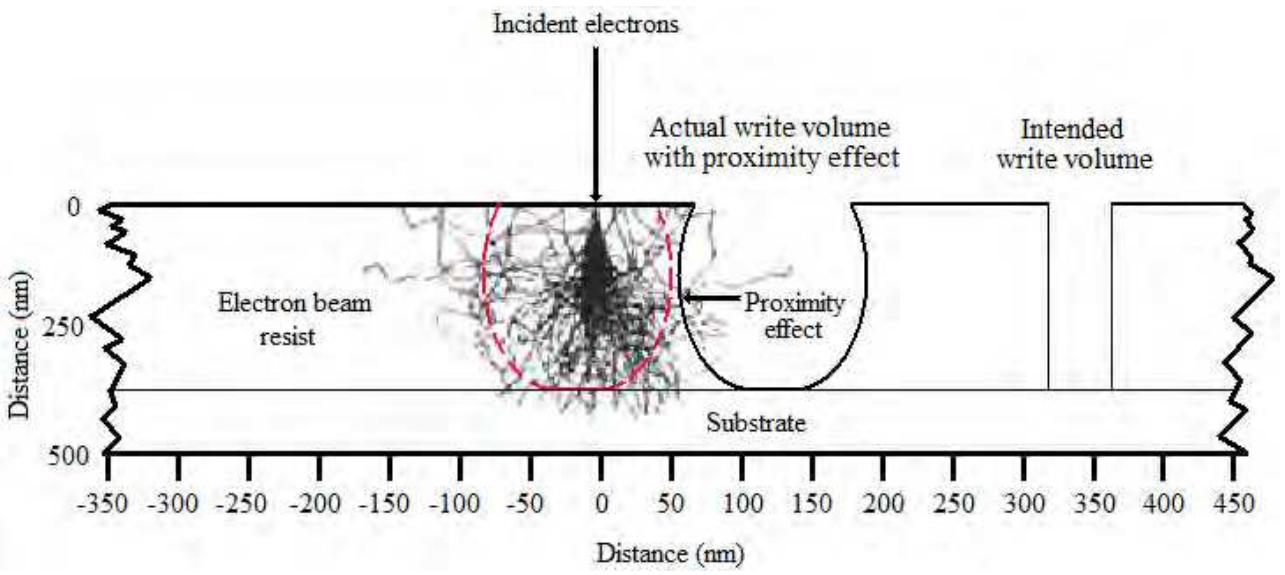

Fig. 2. Schematic of a typical Monte Carlo simulation demonstrating the proximity effect.

The limit of the smallest feature size that can be produced in PMMA is about 10nm, when the resist thickness is approximately $40 \mathrm{~nm}$. At these geometries, the resist cannot be used for lift off, because, if the user wanted to produce a gate structure for a transistor for example, then the power applied to the gate must be extremely low to avoid burning out the structure (due to resistive heating) and cause an open circuit. For high power devices such as Gallium Nitride (GaN) HEMTs used as power amplifier in the next generation mobile phone handsets, lithography via this method is not suitable.

In order to address this lithographic challenge, the current trend is toward the use of nanocomposite resists (Ishii et al., 2000, Ishii et al 1997). These materials can have a large impact on current lithography fabrication technologies thanks to the properties of maintaining high throughput while increasing the aspect ratio of the resist. Nanoparticles can have an enormous effect on important properties of the resist. This has been extensively studied using carbon fullerenes and silica nanoparticles (Ishii et al 2001, Merhari et al 2002). The first requirement for the nanocomposite hybrid material is that the dispersion of the nanoparticles must be well defined. It has often proved difficult to form a stable dispersion of nanoparticles in polymer matrices, as the particles tend to aggregate. The strength of the inter-nanoparticle coupling in liquids typically ranges from weak van der Waals interactions to relatively strong hydrogen bonding. The geometrical form of the nanoparticle aggregates can be string, network, or globular structures. 
The surface nature of these oxide nanoparticle species is hydrophilic due to the existence of hydroxyl groups (Sidorenko et al 1999). In order to embed the nanoparticle in a hydrophobic polymer matrix, the interfacial interaction must be improved. The modification of the nanoparticle surface with different interfacial methods has been applied. Such techniques incorporated the encapsulation of the nanoparticle by an emulsion polymerization in PMMA (Erdem et al., 2000).

The physical properties like electrical, mechanical and optical properties are enhanced by these materials. The type of nanoparticle species can affect the polymer nanocomposite properties, these are determined by its nanostructure, size, shape and concentration and by interactions with the polymer matrix (Yuwono et al., 2005, Lu et al., 2005). These hybrid materials allow the designer to manipulate their physical and chemical properties, are processed with ease and have a relatively low cost (Judeinstein \& Sanchez 1996, Potyrailo 2006). The goal here was that the nanoparticles must not effect or interfere with the process of e-beam lithography.

It is expected that proximity effects can be greatly reduced by nanocomposite resists. This is achieved through the addition of nanoparticles throughout the PMMA polymer reducing the lateral distance of the electrons travelling through the PMMA polymer. This is due to the fact that the density of the nanoparticles can be substantially larger than that of the organic polymer, which reduces the lateral energy spread of secondary electrons. Hence, the nanoparticles have a larger electron energy stopping power. Reducing the proximity effect provides a means of achieving a higher aspect ratio as the overall resist thickness can be increased (Gonsalve et al 2001).

The addition of the nanoparticles will also have a direct effect on the high aspect ratios by increasing the rigidity of the film, as the mechanical properties of the PMMA resist are improved when the concentration of nanoparticles is increased. The nanoparticles will prevent the nanometer features from collapsing, giving rise to a higher achievable aspect ratio. Subsequently, this can lead to a reduction of line broadening and improve the critical dimension of feature sizes. Achieving these improvements will be the subject of the subsequent sections in this chapter.

\section{Oxide nanoparticle stability and DVLO theory}

Three of the fundamental states of matter are solids, liquids and gases. If one of these states is finely dispersed in another then we have a 'colloidal system'. These materials have special properties that are of great practical importance. There are various examples of colloidal systems that include aerosols, emulsions and colloidal suspensions.

An initially formed aggregate is called a cluster and the process of its formation is called clustering. The cluster may or may not sediment or phase separate. If the aggregate changes to a much denser form, it is said to undergo coagulation. An aggregate usually separates out either by sedimentation (if it is more dense than the medium) or by creaming (if it less dense than the medium). The terms clustering and coagulation have often been used interchangeably. Usually coagulation is irreversible whereas clustering can be reversed by the process of declustering. Figure 3 schematically represents some of these processes.

The quality of the nanoparticle dispersion inside the nanocomposite material can be determined by measuring its surface roughness. If the surface roughness is poor then this 


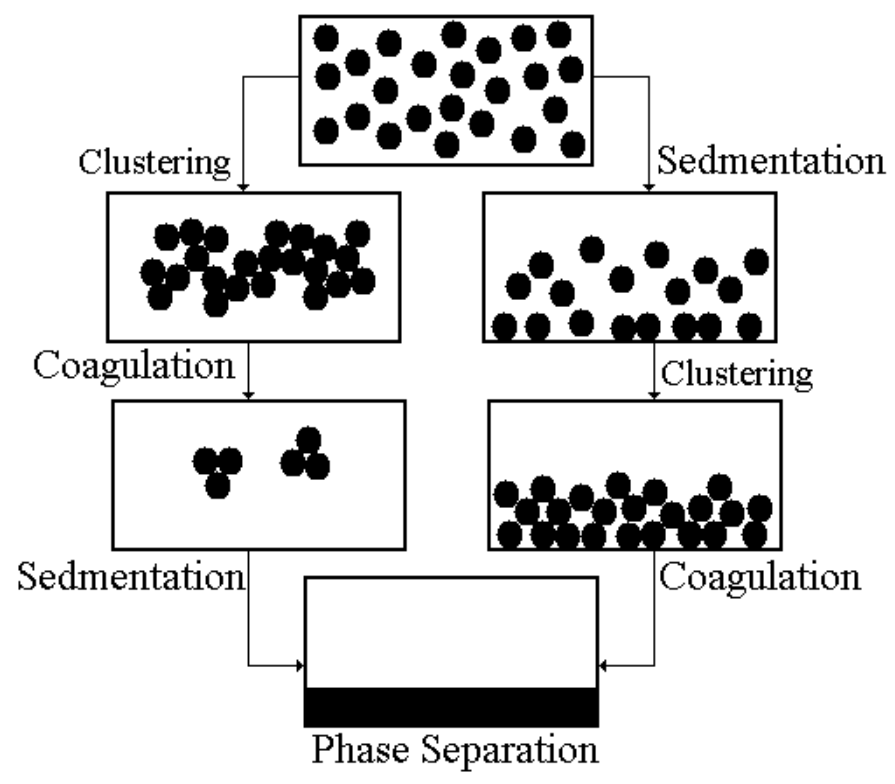

Fig. 3. Schematic diagram showing various mechanisms where stability may be lost in a colloidal dispersion.

indicates that the nanoparticles have clustered together, thus a poor suspension has occurred. This is insufficient for electron beam lithography as the nano structures written in the nanocomposite resist when developed will result with poor edge definition. The value of the surface roughness will depend on the size of the features that are to be fabricated. As a figure of merit the size of the features is below 100nm then the surface roughness must be below 50nm. However, there is a limit to the smallest nano structure that can be produced, that limit is defined by the size of the nanoparticle.

The surface roughness can be measured using a surface probe microscope topometrix explorer in non-contact mode. The Atomic Force Mircoscope (AFM) tips were cantilevers operating at a frequency range of $279-313 \mathrm{kHz}$. The length of the cantileverwas $134 \mu \mathrm{m}$, width $28 \mu$ mand the thickness was $3.7 \mu \mathrm{m}$. The pyramidal tip was $3 \mu \mathrm{m}$ with a base of $10 \mu \mathrm{m}$ high, the tip radius was $<20 \mathrm{~nm}$ and the force applied was $25-38 \mathrm{Nm}^{-1}$. To determine the surface roughness of all the samples, the average was taken of the peaks and troughs, measured in $10 \mu \mathrm{m}$ squares.

It can be clearly seen that the AFM image of figure 4 shows the surface of the nanocomposite film (loaded with $200 \mathrm{mg}$ of nanoparticles) is not homogenous when the oxide nanoparticles are directly dispersed into the PMMA polymer. The rms surface roughness of the $\mathrm{Al}_{2} \mathrm{O}_{3} /$ PMMA nanocomposite surface was $402 \mathrm{~nm}$. This shows that the surface of the nanocomposite resist indicates that the nanoparticles have clustered together. This will affect the Line Edge Roughness (LER) of the nano structures directly written into the nanocomposite resist when developed. Therefore, the nanocomposite resist surface must be 


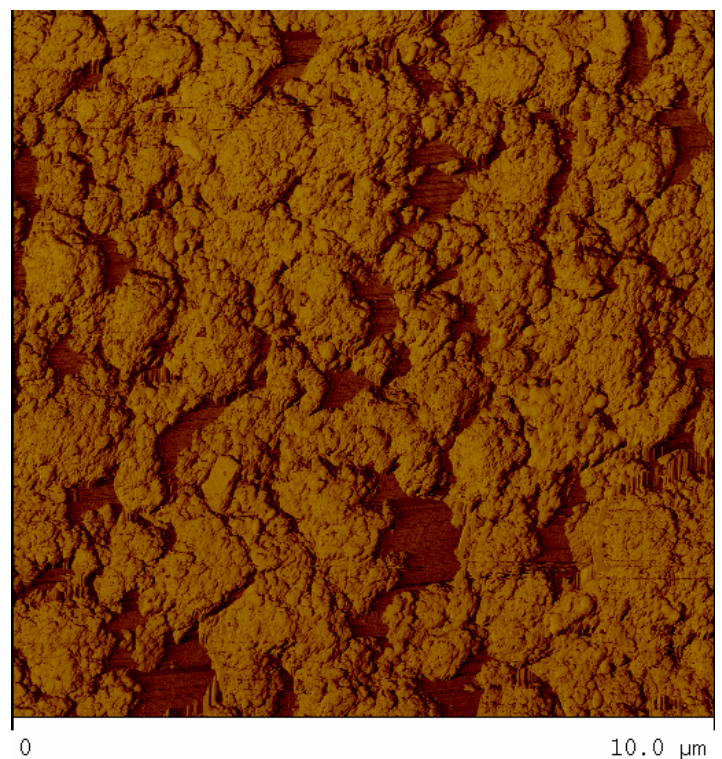

Fig. 4. AFM image of $200 \mathrm{mg}$ of $\mathrm{Al}_{2} \mathrm{O}_{3}$ nanoparticles embedded directly into $1 \mathrm{~g}$ of PMMA/Anisole (7\%).

improved, but first a good level of understanding of the mechanism of nanoparticle/nanoparticle interactions must be gained in order to achieve this goal.

In the 1940s, scientists Derjaguin, Verwey, Landau and Overbeek (DVLO) developed a theory for the stability of colloidal systems (Derjagin \& Landau 1941, Verway \& Overbeek 1948)). DVLO theory proposed that the stability of a particle in a solution was dependent upon its total potential energy function $V_{T}$ and is given by

$$
V_{T}=V_{A}+V_{R}+V_{S}
$$

$V_{S}$ is the potential energy. As the separation occurs near interface at a distance of a few nanometers, this contribution is a small proportion of the energy of the system to the total potential energy. The terms $V_{A}$ and $V_{R}$, are the van der waals attractive and the electrical double layer repulsive forces, these have a larger impact on the particles and function at larger distances. The attraction potential is given by

$$
V_{A}=\frac{-A}{\left(12 \cdot \pi \cdot D^{2}\right)}
$$

where $A$ is the Hamaker constant and $D$ is the particle separation. The repulsive potential $V_{R}$ is given by

$$
V_{R}=2 \pi \varepsilon r \xi^{2} \exp (-\kappa D)
$$

where $\mathrm{K}$ is a function of the ionic composition, $\zeta$ is the zeta potential, $r$ is the particle radius and $\pi$ is the solvent permeability. 
The theory indicates that in order to stabilize the particles in the colloidal system as they advance towards each other due to the Brownian motion, contributions of the attractive van der Waals forces $\left(V_{A}\right)$ and repulsive electrical double layer forces $\left(V_{R}\right)$ and this is also known as a depletion zone, which can be determined by the total potential energy. Therefore, due to this theory the oxide nanoparticles are suspected to unbalance the depletion effect and osmotic pressures in the PMMA/Anisole system. This is illustrated in figure 6. It depicts the three tier system consisting of the PMMA molecule chain indicated in green. To achieve its chain form, the PMMA is dissolved in a solvent called Anisole, shown in red. It can be seen from the illustration that each nanoparticle is surrounded by a depletion zone; this is the region immediately next to each nanoparticle surface (indicated by the dotted line).

The depletion of polymer molecules from the region between closely spaced oxide nanoparticles leads to an effective internanoparticle / nanoparticle attraction. When the nanoparticles are introduced into the PMMA polymer matrix, the unbalanced osmotic pressure pushes the nanoparticles towards one another via Brownian motion. Hence nanoparticle clustering occurs when the depletion regions of two nanoparticles intersect, due to the van der waals attractive forces indicated by the black area in the depletion zones in figure 6. This can be expressed in the form of an attractive pair potential, the depletion potential, $U_{d e p}$

$$
U_{\text {dep }}=\left\{\begin{array}{cc}
+\infty & \text { for } r \leq a \\
-\prod_{p} V_{\text {overlap }} & \text { for } \sigma<r \leq \sigma+2 r_{g} \\
0 & \text { for } r>\sigma+2 r_{g}
\end{array}\right.
$$

where $\sigma=2 a$ is the particle diameter and $\prod_{p}$ is the osmotic pressure of the polymer. $V_{\text {overlap }}$ is the volume of the overlapping

$$
V_{\text {intersect }}=\left(1-\frac{3 r}{2 \sigma(1+\xi)}+\frac{1}{2}\left[\frac{r}{\sigma(1+\xi)}\right]^{3}\right) \frac{\pi}{6} \sigma^{3}(1+\xi)^{3}
$$

where $\xi=r_{g} / a$ is the size asymmetry ratio. The polymer osmotic pressure given here is

$$
\prod_{p}=n p^{(R)} k_{B} T
$$

where $n_{p}{ }^{(R)}$ is the polymer number density.

\section{Dispersion mechanisms and the oxide nanoparticle surface properties}

To improve the dispersion of the oxide nanoparticles, their surface must be encapuslated, so that they will repel each other (hence meeting the requirement of the DVLO theory) and then be homogenously dispersed into the PMMA. Therefore, the nanoparticles must be suspended in a solvent first. It is this parameter that governs its viscosity and overall thickness of the nanocomposite resist. 


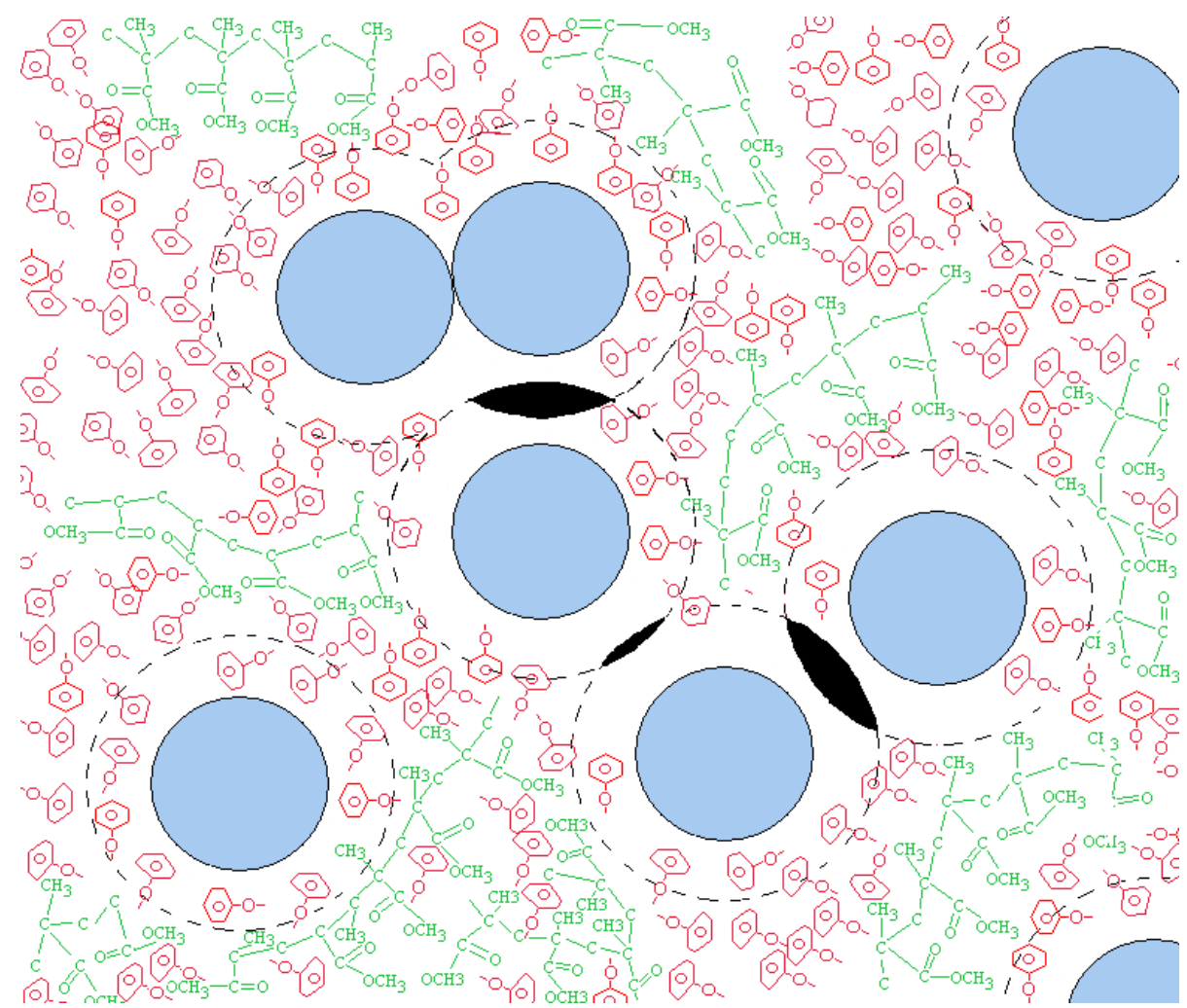

Fig. 6. Schematic representation of the nanoparticle / Anisole /PMMA system.

The stability of the oxide nanoparticle dispersion in the PMMA/anisole can be determined by understanding the behaviour of the bonding mechanism between the various solvents used to disperse the oxide nanoparticles. This will identify which solvents are most appropriate for this task of repelling the nanoparticles. The solvents considered initially were toluene, xylene, anisole, isopropanol (IPA), methanol, acetic acid and deionized water and their properties can be found in table 1. It should be noted that acetone was not used, because, the PMMA molecule breaks down in acetone (acetone is used the strip PMMA from the substrate). The interaction between the surface of the oxide nanoparticles and the encapsulating solvents will determine the effectiveness of the dispersion of the oxide nanoparticles in the solvents. This interaction can be predicted by means of contact angle measurements and a suitable hydrophilic surface. This was achieved by substituting the oxide nanoparticles with borosilicate glass, as the oxide nanoparticles are also hydrophilic.

Each solvent was dropped onto the surface of the borosilicate glass and the contact angle was measured. Due to the nature of the borosilicate glass the solvents with a relatively high polarity index should have a smaller contact angle due to the molecule having $\mathrm{OH}$ groups attached to them. This will lead to hydrogen bonding. The results are shown in figure $7 \mathrm{a}-\mathrm{g}$ and in table 1. 


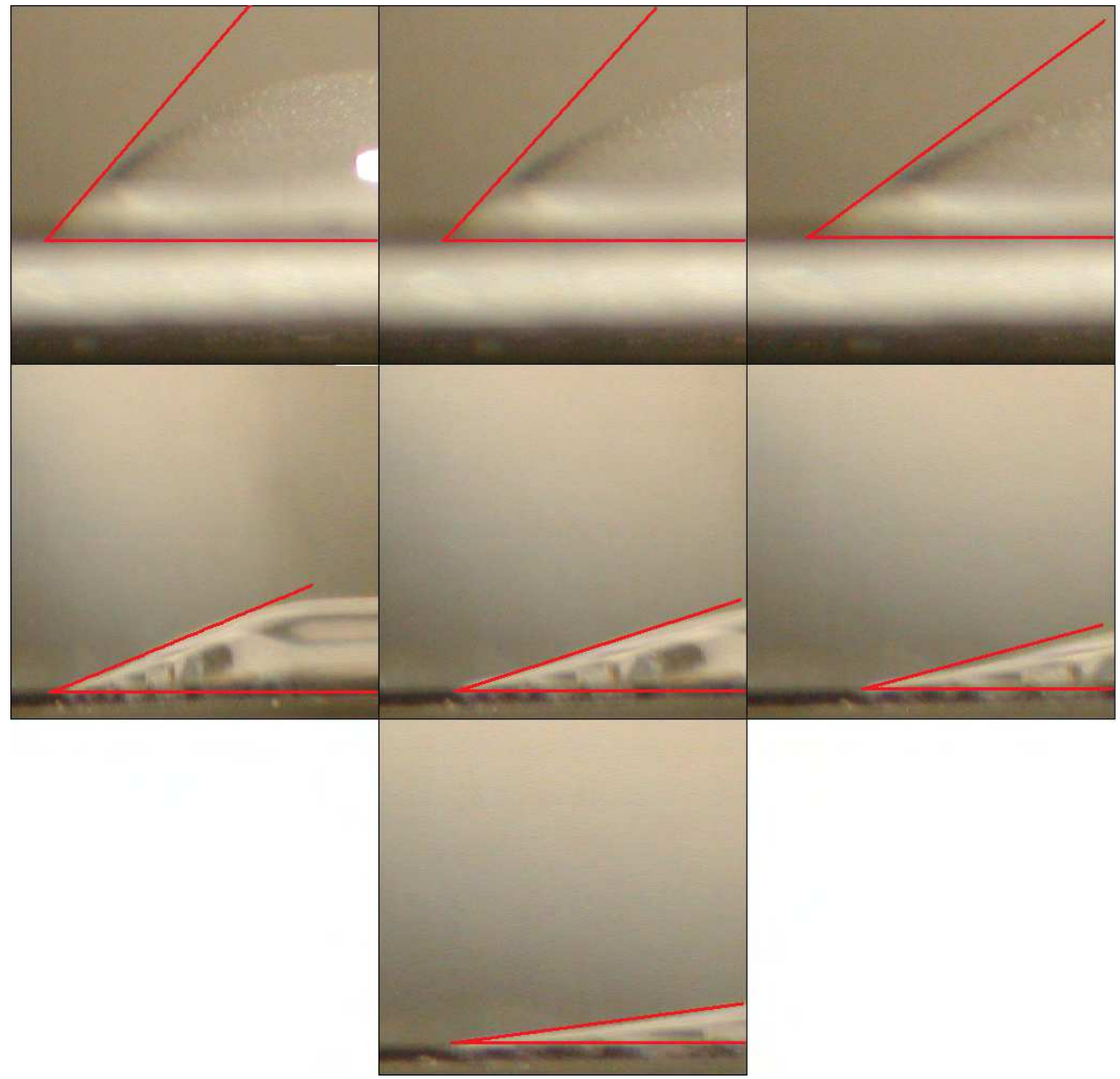

Fig. 7. Contact angles of solvents. a) Toluene, b) Xylene, c) Anisole, d) IPA, e) Methanol, f) Acetic Acid, g) Water.

Table 1 shows the molecule structure of each solvent incorporated in this experiment. It is evident that the solvents (Toluene, Xylene and Anisole) with a polarity index less than four do not have any $\mathrm{OH}$ groups, where as the solvents with a higher polarity index more than four have $\mathrm{OH}$ groups attached to the molecule, hence, hydrogen bonding can take place. Where, the electrical double layer repulsive force will have a larger impact.

It was found from the data shown in figure 8 that in order to achieve a stable oxide nanoparticle suspension, solvent molecules with a polarity index higher than 4.0 are extremely hydrophilic. Due to the nature of these solvents, hydroxyl $(\mathrm{OH})$ groups are attached to them. These $\mathrm{OH}$ groups have a dipole, where the hydrogen atom is bonded with oxygen atom. The electron field is directed from the hydrogen atom towards the oxygen atom pulling electrons away from the hydrogen atom on to the oxygen atom. This causes the hydrogen to have a slight positive charge and the oxygen will become negatively charged. A saturated 


\begin{tabular}{|c|c|c|c|}
\hline Chemical & Molecule Structure & Polarity Index & Contact Angle \\
\hline Toluene & $\begin{array}{l}\mathrm{CH}_{3} \\
\mathrm{CH}_{3}\end{array}$ & 2.4 & $52^{\circ}$ \\
\hline Xylene & $\mathrm{CH}_{3}$ & 2.5 & $49^{\circ}$ \\
\hline Anisole & & 3.8 & $38.5^{\circ}$ \\
\hline IPA & ${ }_{\mathrm{H}} \stackrel{\mathrm{H}}{\mathrm{H}}_{\mathrm{H}}$ & 4.0 & $22^{\circ}$ \\
\hline Methanol & $\mathrm{H}-\underset{\mathrm{H}}{\mathrm{C}}-\mathrm{OH}$ & 5.1 & $18^{\circ}$ \\
\hline Acetic Acid & $-\underset{\mathrm{H}}{\mathrm{C}}-\mathrm{C}-\mathrm{OH}$ & 6.2 & $14^{\mathrm{o}}$ \\
\hline Water & $\mathrm{H}_{2} \mathrm{O}$ & 9 & $7.5^{\circ}$ \\
\hline
\end{tabular}

Table 1. Solvent molecules and contact angle.

oxygen atom in a covalent compound can have two single bonds and be bonded to other atoms; these use two of the oxygen outer shell electrons. The other four electrons form a couple of lone pair orbitals, these lone pairs and the single two bonds are arranged in a tetrahedral lattice around the oxygen. A positively charged atom can form an extra bond to another molecule (oxygen needs to be in a bonded state) by inserting itself into a lone pair orbital on the hydrogen atom.

Therefore, hydrogen bonding between the solvent (polarity index higher than 4.0) will stabilize the oxide nanoparticle suspension, (this can be seen from table 1). These solvents, with a polarity index lower than 4.0 are aromatic. They are formed around a conjugated ring, which do not have hydroxyl groups attached to them. Hence, these substances can not bond to the oxide nanoparticle via the hydrogen bonding method, as illustrated in figure 9 . 


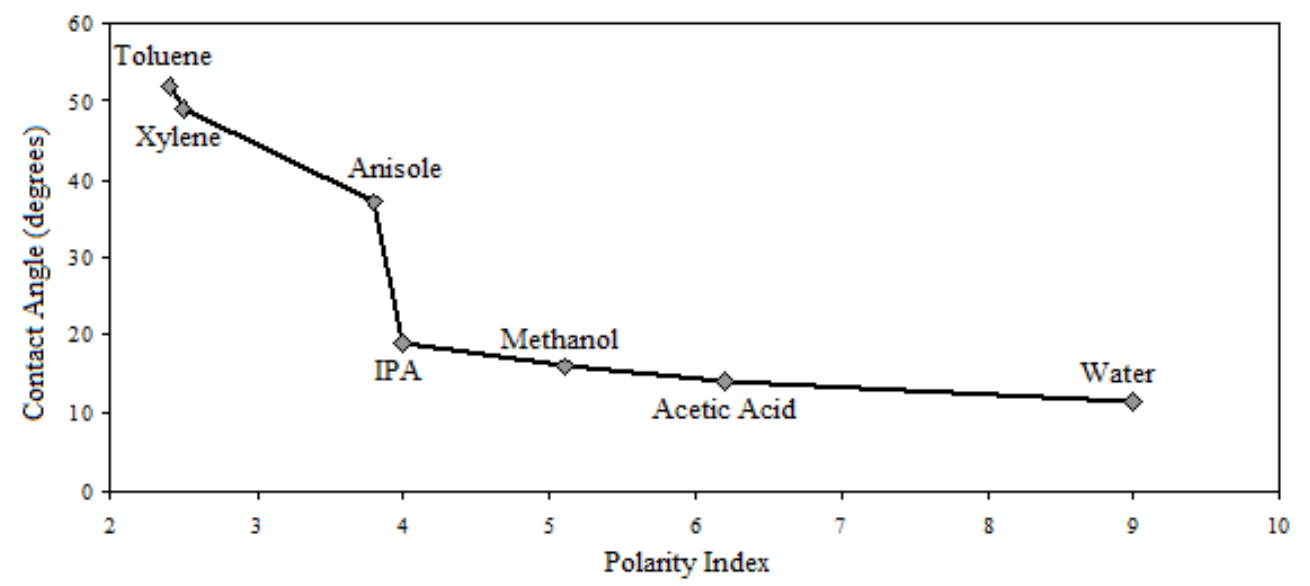

Fig. 8. Contact angles of the solvents shown in the previous figure (Lewis et al., 2010).

Figure 9 gives a schematic representation of the mechanism of hydrogen bonding, it can be seen clearly that the Toluene, Xylene and Anisole cannot suspend the oxide nanoparticle because there is no mechanism for hydrogen bonding process to occur. This is because the dipoles within the hydroxyl groups are not present. There is no barrier immediate to the surface of the oxide nanoparticle. This allows the depletion region around each oxide nanoparticle to intersect and therefore, the oxide nanoparticles are attracted to one another, hence, clustering.

Clustering of the oxide nanoparticles can be greatly reduced by using IPA, Methanol, Acetic Acid or Water. Figure 9 illustrates that these molecules have hydroxyl groups within them and are attracted to the hydroxyl groups at the surface of the oxide nanoparticles via their dipoles. Therefore, they surround the oxide nanoparticle and form a physical barrier with a thickness greater than that of the depletion region which would surround the oxide nanoparticle (see figure 6). The depletion regions of the oxide nanoparticles can never intersect. Hence, the oxide nanoparticle attraction is greatly reduced and the oxide nanoparticle suspension is stable.

Due to the fact that the PMMA polymer is dissolved in Anisole, it is evident that when the oxide nanoparticles were dispersed directly into the PMMA polymer matrix / Anisole system they would never be suspended homogeneously. The solvents used were Methanol and Toluene, the reason for this choice was that Methanol was more hydrophilic (contact angle of $18^{\circ}$ ) than Toluene (contact angle of $52^{\circ}$ ) as they have an index polarities of 5.1 and 2.4 respectively. As the homogeneous dispersal of the oxide nanoparticles could be ambiguous, the performance of the suspension was measured using the zeta potential measurement system.

\section{Oxide nanoparticle stability}

The Zeta potential is a physical property that is generally applied to evaluate the stability of a colloidal system. The solvent that surrounds the particle comprises of an inner region which is called the stern layer and an outer region called the diffuse layer (this makes up the electrical double layer). The first component has strong ions bound to it, while the strength 


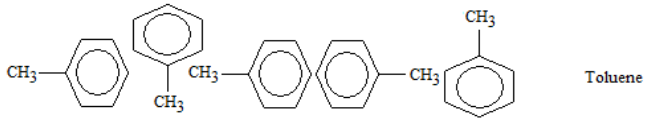

$\mathrm{OH} \mathrm{OH} \mathrm{OH} \mathrm{OH} \mathrm{OH} \mathrm{OH} \mathrm{OH} \mathrm{OH} \mathrm{OH} \mathrm{OH} \mathrm{OH} \mathrm{OH} \mathrm{OH} \mathrm{OH} \mathrm{OH} \mathrm{OH} \mathrm{OH} \mathrm{OH} \mathrm{OH \longleftarrow -Hydroxyl} \mathrm{Groups}$

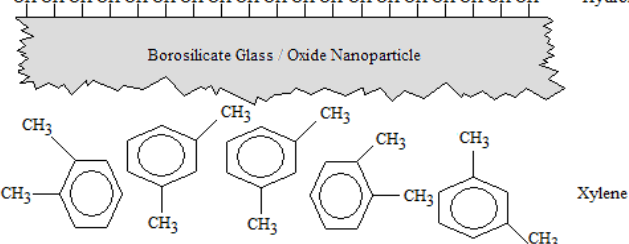

$\mathrm{OH} \mathrm{OH} \mathrm{OH} \mathrm{OH} \mathrm{OH} \mathrm{OH} \mathrm{OH} \mathrm{OH} \mathrm{OH} \mathrm{OH} \mathrm{OH} \mathrm{OH} \mathrm{OH} \mathrm{OH} \mathrm{OH} \mathrm{OH} \mathrm{OH} \mathrm{OH} \mathrm{OH} \stackrel{\mathrm{CH}_{3}}{\longleftarrow}$ Hydroxyl Groups
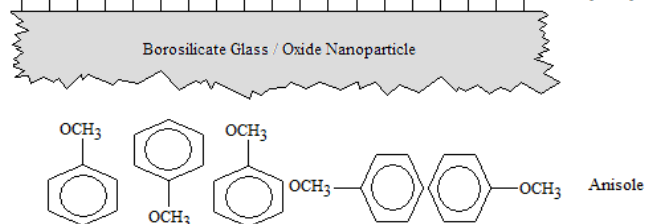

$\mathrm{OH} \mathrm{OH} \mathrm{OH} \mathrm{OH} \mathrm{OH} \mathrm{OH} \mathrm{OH} \mathrm{OH} \mathrm{OH} \mathrm{OH} \mathrm{OH} \mathrm{OH} \mathrm{OH} \mathrm{OH} \mathrm{OH} \mathrm{OH} \mathrm{OH} \mathrm{OH} \mathrm{OH \longleftarrow} \longleftarrow$ Hydroxyl Groups

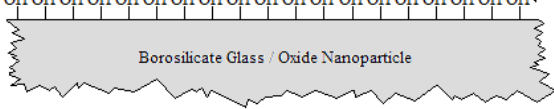

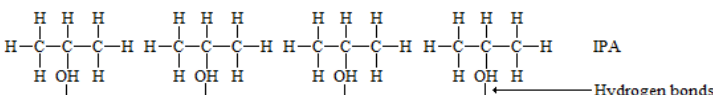
OH OH OH OH OH OH OH OH OH OH OH OH OH OH OH OH OH OH OH๖ Hydrogen bonds

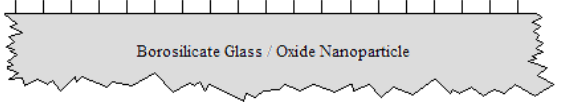

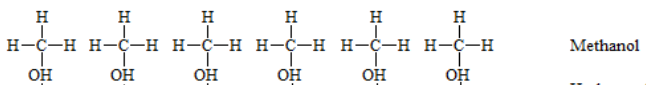

OH OH OH OH OH OH OH OH OH OH OH OH OH OH OH OH OH OH OH־ -Hydrogen bonds
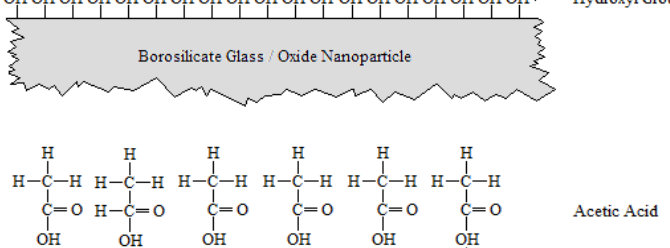

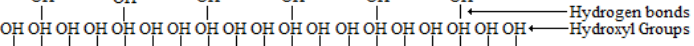

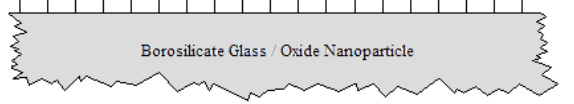

$\begin{array}{llllllllllll}\mathrm{H}_{2} \mathrm{O} & \mathrm{H}_{2} \mathrm{O} & \mathrm{H}_{2} \mathrm{O} & \mathrm{H}_{2} \mathrm{O} & \mathrm{H}_{2} \mathrm{O} & \mathrm{H}_{2} \mathrm{O} & \mathrm{H}_{2} \mathrm{O} & \mathrm{H}_{2} \mathrm{O} & \mathrm{H}_{2} \mathrm{O} & \mathrm{H}_{2} \mathrm{O} & \text { Water }\end{array}$

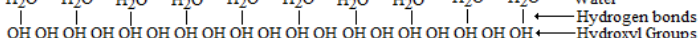

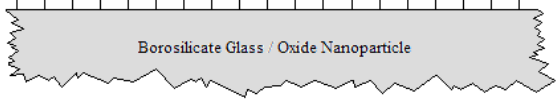

Fig. 9. Hydrogen bonding mechanism between the borosilicate glass / oxide nanoparticle surface and the various solvents. 
of the ions of the secondary component are weakly associated. However, ions and particles can be stabilized due to the theoretical boundary within the diffuse layer. However, ions and particles can be stabilized due to the theoretical boundary within the diffuse layer. The potential at this boundary is called the zeta potential and this is illustrated in figure 10.

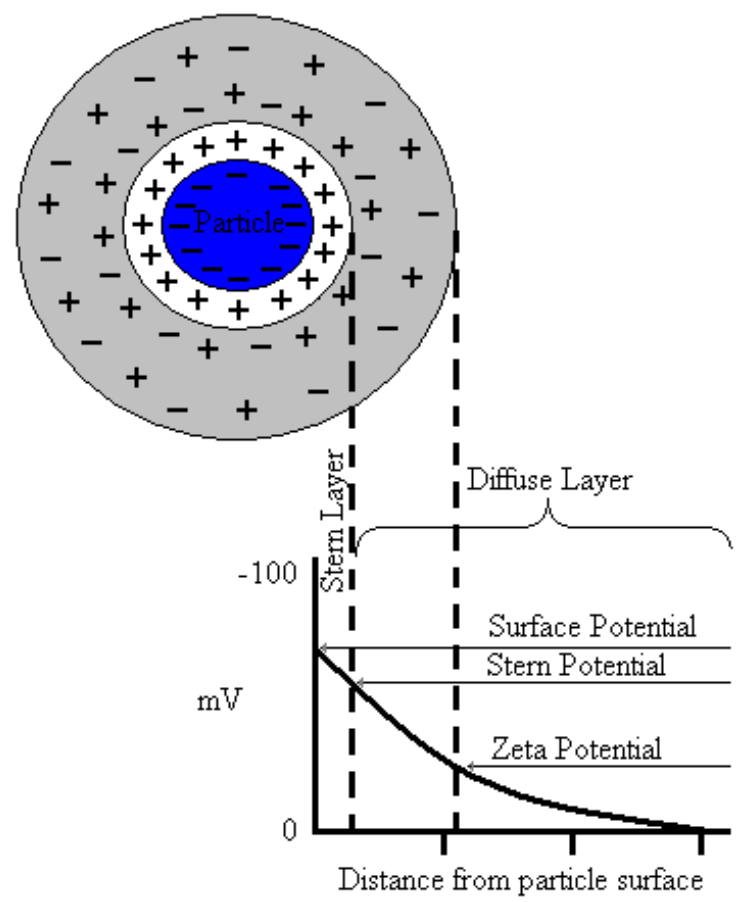

Fig. 10. Schematic representation of zeta potential.

The potential stability of the nanoparticle system is indicated by the magnitude of the zeta potential parameter. All the particles in the suspension will tend to repel each other if they have a large positive or negative zeta potential of $30 \mathrm{mV}$ or $-30 \mathrm{mV}$, therefore, particle clustering will not occur given rise to a stable colloidal system. But, if the zeta potential value is low, then the particles will cluster because there is no force to repel them. The knowledge of the zeta potential can reduce the time taken to manufacture trial formulations and assist in forecasting long term stability.

The electrophoretic mobility parameter is directly related to the zeta potential parameter, and this is given by the Henry equation

$$
U_{E}=\frac{2 \varepsilon \xi f(\kappa r)}{3 \eta}
$$

where $U_{E}$ is the electrophoretic mobility, $\eta$ is the viscosity and $f(\kappa a)$ is the Henry's function. The Debye length is termed in units of $\mathrm{k}$. Its reciprocal length $\mathrm{K}^{-1}$ is the measure of the thickness of the electrical double layer. Due to the fact that the term $r$ is the radius of the particle, then $\mathrm{k} r$ measures the ratio of the particle radius to the electrical double layer thickness. 
To measure the electrophoretic mobility, charged particles suspended in the electrolyte are attracted towards the electrode of opposite charge under the influence of an electric field. The forces acting on these particles are likely to resist this motion. When the particles travel with a constant velocity, the two resisting force have reached an equilibrium condition. This is dependent upon the strength of the electric field, the dielectric constant of the suspending medium and its viscosity and the zeta potential. Therefore, the electrophoretic mobility is the velocity of a particle in a unit electric field.

From the Aluminium oxide $\left(\mathrm{Al}_{2} \mathrm{O}_{3}\right)$ nanoparticles directly suspended in Methanol and Toluene, figure 11 shows, that Methanol suspends the oxide nanoparticles successfully. The zeta potential peaks shows that $\mathrm{Al}_{2} \mathrm{O}_{3}$ nanoparticles are both positive. From the data here, it can be seen that the nanoparticles suspended in Methanol have a zeta potential above the $30 \mathrm{mV}$ threshold, therefore the nanoparticle suspension was stable, however, both nanoparticle species suspended in Toluene are below the zeta potential threshold, hence nanoparticle instability, where the zeta potential value was $19.4 \mathrm{mV}$. It was observed that Methanol was effective in suspending the oxide nanoparticles, prior to dispersal within the PMMA polymer. It was found that $200 \mathrm{mg}$ of nanoparticles aggregated together and dropped out of suspension under the force of gravity, on average in less than one minute in $0.5 \mathrm{ml}$ of Toluene, whereas the methanol suspended the same concentration of nanoparticles for many days. Methanol encapsulates the surface of nanoparticles and acts as a barrier so the depletion regions do not intersect. Therefore, the Figure 13 shows the $\mathrm{Al}_{2} \mathrm{O}_{3}$ nanoparticles treated with methanol and suspended directly in the PMMA polymer the rms roughness was $63 \mathrm{~nm}$. Thus, as more nanoparticles are embedded in the PMMA, then the surface roughness is increased. However, the surface of the nanocomposite film has been improved by a factor of 6.34 times. This is more suitable for the electron beam lithographic application, because the surface roughness is considerably reduced, hence the pattern remains intact.

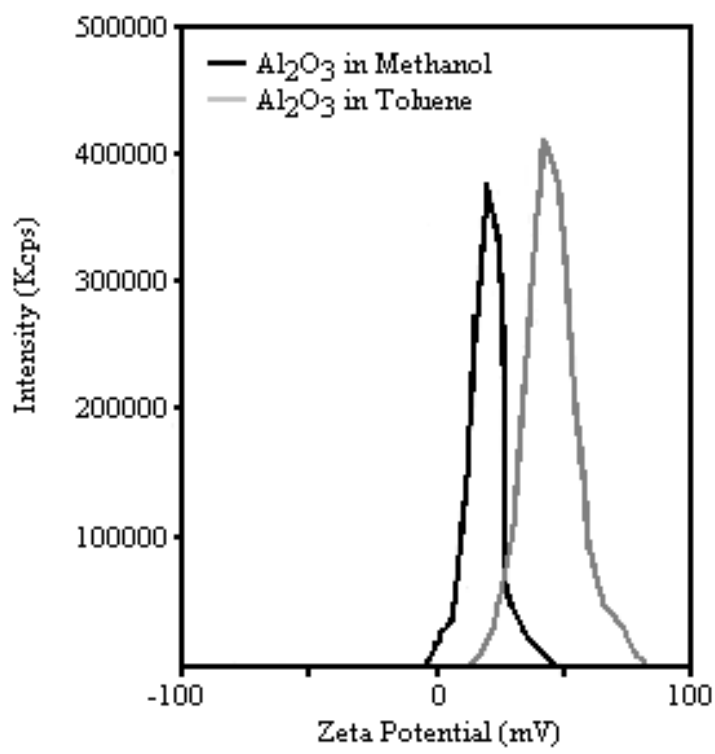

Fig. 11. Zeta potential of the two test cases $-\mathrm{Al}_{2} \mathrm{O}_{3}$ suspended in methanol and toluene respectively (Lewis et al., 2010). 


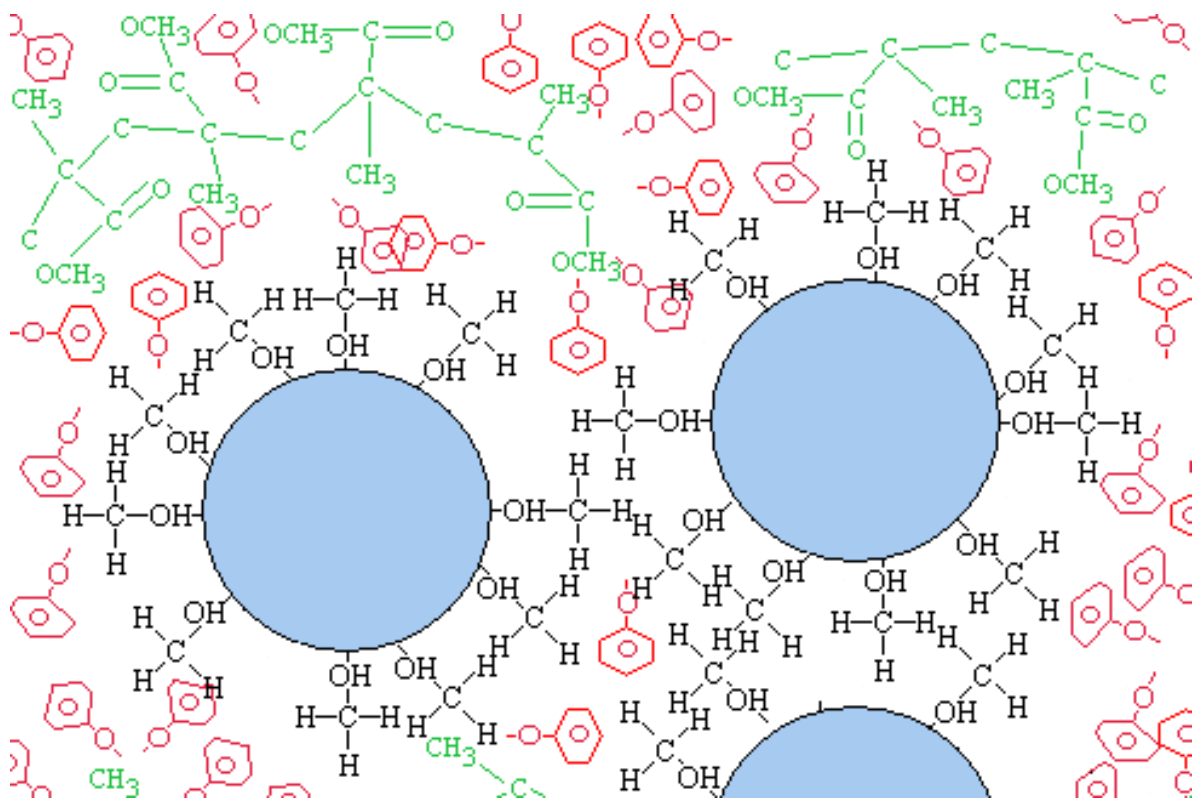

Fig. 12. Schematic representation of the nanoparticle / Methanol / Anisole / PMMA system.

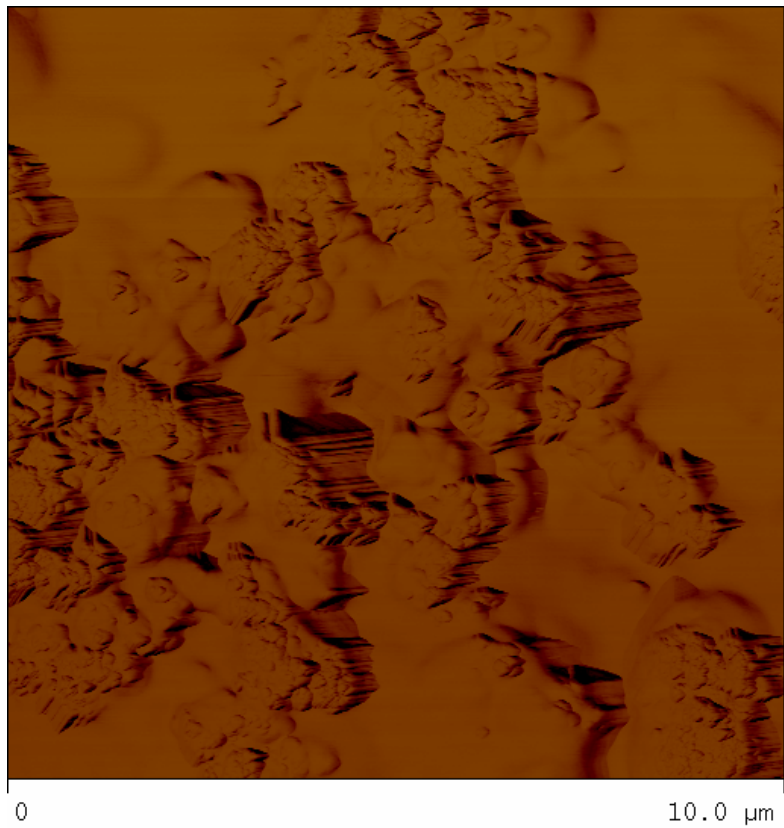

Fig. 13. AFM image of $\mathrm{Al}_{2} \mathrm{O}_{3}$ nanoparticles embedded in the PMMA matrix that was suspended in Methanol (Lewis et al., 2010). 


\section{Characterization of the nanocomposite resist using Electron Beam Lithography}

Since the early 1970's it has been recognized that by accelerating a focused beam of electrons at the surface of a resist, a very high resolution pattern can be produced, where the wavelength of electrons are smaller than the photons of ultra violet radiation by more than three orders of magnitude (Livesay \& Fritz 1972).

For electron beam lithography, it is most important to determine the clearing dose of the resist material. This is defined by the exposure parameters that allows the electron to penetrate the resist to achieve excellent pattern definition and this is governed by the area dose and is given by

$$
\text { Area Dose }=\frac{I^{*} t}{S^{2}}
$$

Where $I$ is the current of the incident beam, $t$ is the dwell time, which is the time taken for the electrons to penetrate the resist and $S$ is the step size. This is the parameter that governs the position that the beam moves from one position to its next position. Figure 14 shows a schematic representation of the step size parameter to demonstrate its impact to the proximity effect. As the electron beam is scanned over the surface of the resist from position a to position $b$, the electrons penetrate the resist. It can be seen that the foot print is larger at the bottom of the resist than at the top. Therefore, if the electron beam is placed too close to the previous position (as indicated by position a) that was already exposed, then the new exposure will intersect (illustrated by the red line) with the last exposure and this contributes to the proximity effect. Thus has been over exposed. This will have direct effect on the definition of the pattern. However, if the electron beam is placed too far away from the previous exposure as shown by position $\mathrm{d}$ and e in figure 14. The result of the pattern will become under exposed. Therefore, the step size must be balanced as seen by c and $\mathrm{d}$. Here both exposures are placed by enough distance part from each other, so that they intersect at the bottom of the resist and this is illustrated by the red line.

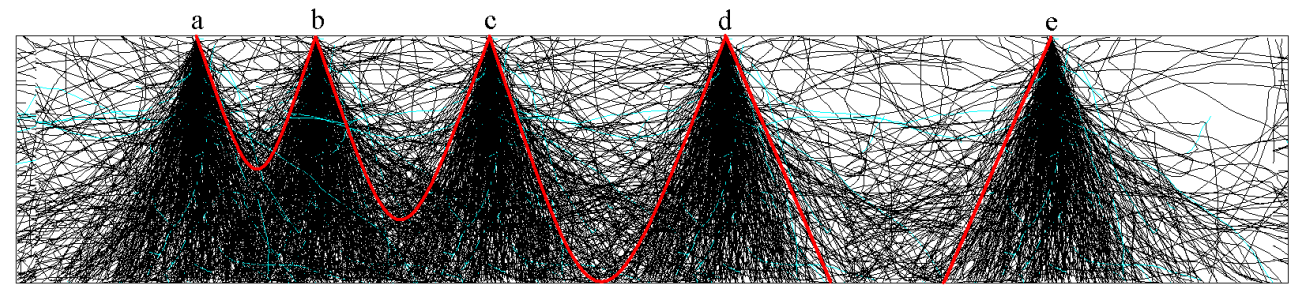

Fig. 14. Schematic representation of the step size parameter.

Over exposure may also result if the current $I$ is too large as more SE can be generated as they scatter from the atoms at an angle of 80 . Figure 15 shows an SEM image of examples of resist that has been over exposed. As the resist profile has an under cut. If the current density is reduced then this may result in under exposure, where the electrons have not completely penetrated through the resist.

Of course, in reality this is dependent upon thickness. The current and step size can be reduced, if the thickness was decreased then the scattering events inside the resist would 


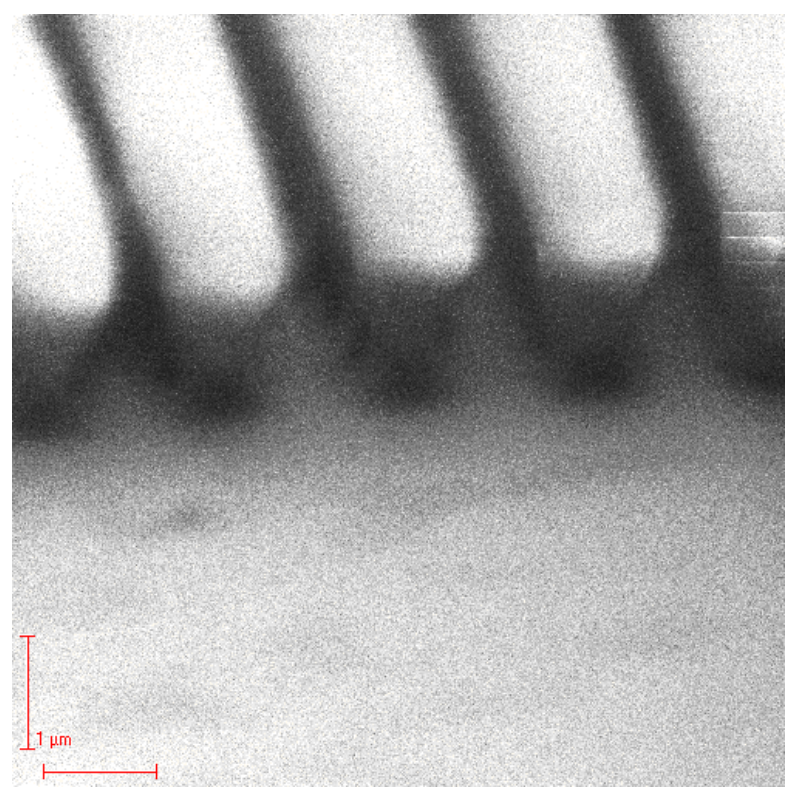

Fig. 15. An SEM image of over exposed resist.

also be decreased. This reduces the proximity effect because the number of electrons (current density) must be enough to overcome the stopping power of the atoms in the resist. This is due to as an electron collides with the atoms in the resist molecule, they will scatter in arbitrary directions. As this occurs, a fraction of this energy associated to that electron will be lost. This process will be repeated more frequently from this point onward until all its energy has been lost. If the resist thickness is large and associated energy is small (e.g. $10 \mathrm{KeV}$ ) the then more collisions will occur and the electrons will scatter and generate SE which will damage the resist in a lateral direction as well as a vertical direction, thus, contributing to the proximity effect.

Both standard PMMA and nanocomposite resists were exposed to the electron beam, which had an acceleration voltage of $25 \mathrm{kV}$ and beam current of $30 \mathrm{pA}$ at a working distance of $7 \mathrm{~mm}$. This was achieved using a Scanning Electron Microscope (SEM), Cambridge S360, which was driven by Elphy quantum pattern generator. To determine the thickness and the appropriate exposure clearing dose, the exposure pattern consisted of a matrix of a hundred $20 \mu \mathrm{m}$ squares, this allowed for accurate AFM measurements of the remaining resist thickness for each dose. These squares were exposed with a dose scaled in incremental steps of $30 \mu \mathrm{C} / \mathrm{cm}^{2}$, up to a highest dose of $600 \mu \mathrm{C} / \mathrm{cm}^{2}$. Hence, the clearing dose could be accurately determined of each resist. The exposure pattern was developed using solution of MIBK (Methyl IsoButyl Ketone) and IPA (IsoProPanol), in the ratio of 1:3, for 30s followed by a 40 s rinse in IPA.

It was found that the standard PMMA 950K 7\% had a thickness of 407nm. However, when $150 \mathrm{mg}$ of $\mathrm{Al}_{2} \mathrm{O}_{3}$ nanoparticles was introduced into the PMMA $950 \mathrm{~K} 7 \%$ polymer matrix, the overall resist thickness was increased to $562 \mathrm{~nm}$. Figure 16 indicates that the exposure clearing doses of PMMA 950K 7\% resists increased as the density of $\mathrm{Al}_{2} \mathrm{O}_{3}$ nanoparticles embedded into the PMMA was increased. The combination of the increased resist thickness 
and the $\mathrm{Al}_{2} \mathrm{O}_{3}$ nanoparticles resulted in higher exposure doses being required in order for the chain scission process to occur throughout the nanocomposite resist.

Looking in more detail at Figure 16, the exposure clearing doses of the standard PMMA $950 \mathrm{~K} 7 \%$ were in the range of $180-210 \mu \mathrm{C} / \mathrm{cm}^{2}$, while when it was loaded with $150 \mathrm{mg}$ of $\mathrm{Al}_{2} \mathrm{O}_{3}$ nanoparticles the clearing doses were in the range of $240-270 \mu \mathrm{C} / \mathrm{cm}^{2}$, as determined from the dose scale. It should be noted that this exposure matrix method only gives a dosage range (e.g $240-270 \mu \mathrm{C} / \mathrm{cm}^{2}$ ) within which complete resist exposure occurs. However, an estimate of the exact clearance dose can be obtained by extrapolation from the data set up to but not including - the final point (where the resist thickness is zero). This method gives a clearance dose of $200 \mu \mathrm{C} / \mathrm{cm}^{2}$ for the standard PMMA case, while the clearance doses was $265 \mu \mathrm{C} / \mathrm{cm}^{2}$ for PMMA 950K 7\% loaded with 150mg. These exposure doses found here are only valid for this resist system and that particular thickness. As the concentration of $\mathrm{Al}_{2} \mathrm{O}_{3}$ nanoparticles increases, the clearing dose had to be increased because the nanoparticles act as electron scattering centres and consequently decrease the electron momentum (Ishii et al 2001).

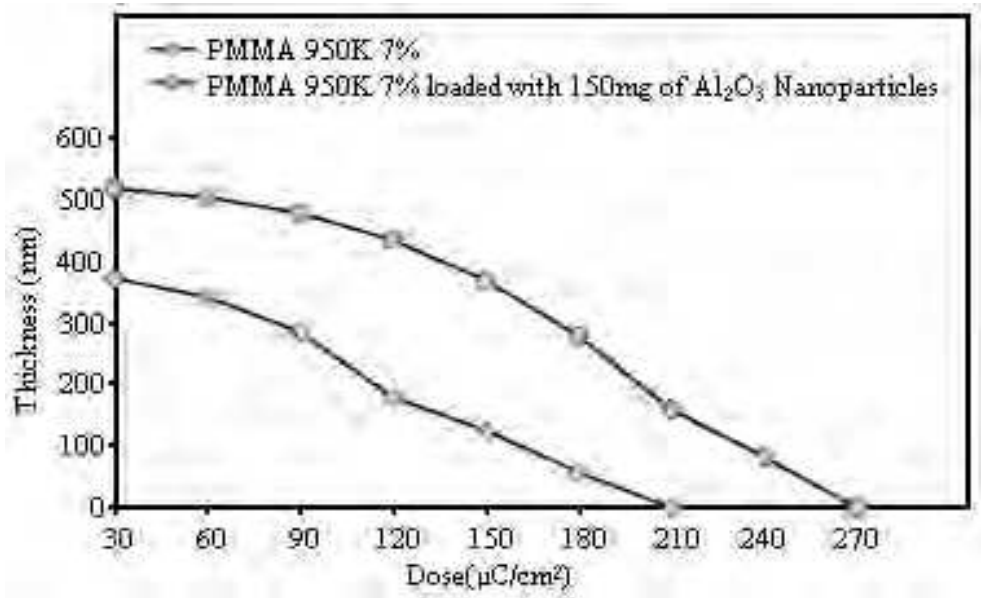

Fig. 16. Exposure doses of nanocomposite resist.

The $\mathrm{Al}_{2} \mathrm{O}_{3}$ nanoparticles also increased the overall resist thickness and therefore the electron exposure dose must be increased to overcome this.

\section{Modeling the effects of the nanocomposite resist using the Monte Carlo Method}

From the results of the previous section it is obvious that the introduction of $\mathrm{Al}_{2} \mathrm{O}_{3}$ nanoparticles in an electron beam resist effects the interaction between the impinging electrons and the atoms in the resist film. The $\mathrm{Al}_{2} \mathrm{O}_{3}$ nanoparticles exhibit different scattering behaviour than the traditional atoms contained in the PMMA electron beam resist, such as Carbon, Oxygen and Hydrogen. Here, the influence of the $\mathrm{Al}_{2} \mathrm{O}_{3}$ nanoparticles in the PMMA electron beam resist was studied through Monte Carlo simulations. This was determined by characterizing the scattering behaviour of the point electron distributions of the PMMA based nanocomposite resist. 
The effect of the $\mathrm{Al}_{2} \mathrm{O}_{3}$ nanoparticle density was studied by comparing the standard PMMA with the PMMA based nanocomposite resist in a constant unit volume of PMMA. Therefore, the effects of nanoparticle density on the interaction with incident electrons can be fully examined.

The Monte Carlo simulation that is presented here calculates electron scattering trajectories in materials, in this case PMMA based nanocomposite resist. The physical properties of the resist were calculated using the weighted percent of nanoparticles to PMMA. PMMA has a density of $1.19 \mathrm{~g} / \mathrm{cm}^{3}$ and $\mathrm{Al}_{2} \mathrm{O}_{3}$ has a density of $4 \mathrm{~g} / \mathrm{cm}^{3}$. The total density of the nanocomposite resist was calculated using,

$$
\rho_{\text {resist }}=\omega \rho_{\mathrm{Al}_{2} \mathrm{O}_{3}}+(1-\omega) \rho_{P M M A}
$$

Where $\rho$ is the density of each material and $\omega$ was the weighted percent of $\mathrm{Al}_{2} \mathrm{O}_{3}$ to PMMA. The atomic weight of PMMA here was $950000 \mathrm{~g} / \mathrm{mol}$ and the atomic weight of $\mathrm{Al}_{2} \mathrm{O}_{3}$ is $101.96 \mathrm{~g} / \mathrm{mol}$.

The nanocomposite resist was considered to have a homogeneous dispersion of $\mathrm{Al}_{2} \mathrm{O}_{3}$ nanoparticles throughout. As the electron travels through the resist it collides either elastically or inelastically with a molecule of PMMA or with a nanoparticle. When the electron collides with an atom, it was decided using the weighted percent of $\mathrm{Al}_{2} \mathrm{O}_{3}$ to PMMA and comparing it with a randomly generated number between 0 and 1 . Whether it is an elastic or inelastic collision was decided by comparing a randomly generated number with the probability of getting an inelastic collision, the ratio between the inelastic cross section and the total cross section. Depending on the type of collision, the scattering cross sections and the mean free path are calculated.

For both elastic and inelastic scattering, the total scattering cross section is calculated again using the weighted percent of $\mathrm{Al}_{2} \mathrm{O}_{3}$ to PMMA,

$$
\sigma_{\text {total }}=\omega \sigma_{\mathrm{Al}_{2} \mathrm{O}_{3}}+(1-\omega) \sigma_{P M M A}
$$

To decide the outcome of the collisions as either elastic or inelastic a random number was generated. This was dependent upon the ratio of the elastic and inelastic scattering cross sections to the total scattering cross section. The next random number decides if the electron has collided with an $\mathrm{Al}_{2} \mathrm{O}_{3}$ nanoparticle or an atom in the PMMA molecule and compares this event to the nanoparticle loading in the polymer film. When this has been achieved, the Monte Carlo procedure calculated energy losses are calculated, and the scattering angles for the collision event.

The elastic scattering cross section is calculated using the screened Rutherford elastic cross section,

$$
\sigma_{\text {elastic }}=\frac{Z^{2}}{E^{2}} \frac{4 \pi}{\alpha(1+\alpha)}\left(\frac{E+511}{E+1024}\right)^{2} \mathrm{~cm}^{2} / \text { atom }
$$

Where $E$ is the electron energy in $\mathrm{KeV}, \mathrm{Z}$ is the atomic number of the material and a is the screening factor, this compensates for the fact that the electron does not see the all of the atom's charge as it is surrounded by a cloud of electrons. 
For the case of inelastic scattering from the nanoparticles, the scattering cross section is calculated by considering only the coulomb interaction between the electron and the atom. In this case the inelastic scattering cross section per electron is,

$$
\frac{d \sigma_{\text {inelastic }}}{d \Omega}=\frac{\pi e^{4}}{E^{2}}\left(\frac{1}{\Omega^{2}+(1-\Omega)^{2}}\right)
$$

Where $\Omega E$ is the energy of the secondary electron produced. The inelastic scattering event causes the primary electron to be deflected by an angle a given by,

$$
\sin ^{2} \alpha=\frac{2 \Omega}{2+t-t \Omega}
$$

Where $t$ is the kinetic energy of the electron in units of its rest mass. However the secondary electron created exits the collision at an angle $\gamma$ given by,

$$
\sin ^{2} \gamma=\frac{2(1-\Omega)}{2+t \Omega}
$$

For an impact that transfers approximately $500 \mathrm{eV}$ to the secondary electron, the primary scatters at an angle of about $1^{\circ}$ and the secondary electron exits at an angle of about $80^{\circ}$. This is why the secondary electrons play a major role in producing the so called 'proximity effect'.

Once the scattering cross sections are calculated, the mean free path of the electron must be calculated. This is the sum of the inelastic mean free path and elastic mean free path of the electron.

$$
\frac{1}{\lambda_{\text {total }}}=\frac{1}{\lambda_{\text {elastic }}}+\frac{1}{\lambda_{\text {inelastic }}}
$$

The elastic and inelastic mean free paths are calculated from the scattering cross sections,

$$
\begin{gathered}
\lambda_{\text {elastic }}=\frac{A}{N_{a} \rho \sigma_{\text {elastic }}} \\
\lambda_{\text {inelastic }}=\frac{A}{N_{a} Z \rho \sigma_{\text {inelastic }}}
\end{gathered}
$$

where $A$ is the atomic weight of the material, $\mathrm{Na}$ is Avogadro's number, $\rho$ is the density of the resist and $\sigma$ is the respective scattering cross section. The total elastic and inelastic mean free path is calculated using weighted percentages,

$$
\frac{1}{\lambda}=\frac{\omega}{\lambda_{\mathrm{Al}_{2} \mathrm{O}_{3}}}+\frac{1-\omega}{\lambda_{P M M A}}
$$

From the value of the mean free path, the distance the electron will travel before it collides again can be calculated. This is done using the step size equation given by,

$$
s=-\lambda \ln (R N D)
$$


where $\lambda$ is the total mean free path and RND is a random number between 0 and 1 . This gives a distribution of step sizes with an average step size of $\lambda$. Therefore, the probability of obtaining a step size near the mean free path is larger than obtaining a step size much larger or smaller than the mean free path.

The final step of the Monte Carlo simulation was to calculate the energy lost by the electron during the scattering event. This was done using the modified Bethe equation for the stopping power of a material and is given by (Newbury \& Myklebust 1981, Luo \& Joy 1989),

$$
\frac{d E}{d S}=78500 \frac{Z}{A E} \ln \left(\frac{1.166(E+0.85 J)}{J}\right)
$$

where $J$ is the mean ionization potential of the material, which was 145 and $74 \mathrm{eV}$ for $\mathrm{Al}_{2} \mathrm{O}_{3}$ and PMMA respectively [6]. Every time the electron scatters, this value is calculated and was subtracted from the current energy of the electron. Once the electron's energy falls below $0.5 \mathrm{keV}$, the electron was no longer tracked as the distance it travels in the material is very small.

The model was used to determine the influence of the $\mathrm{Al}_{2} \mathrm{O}_{3}$ nanoparticles when a primary beam of electrons was incident upon it. The resist films considered here consisted of standard PMMA and PMMA loaded with $150 \mathrm{mg}$ of $\mathrm{Al}_{2} \mathrm{O}_{3}$ nanoparticles, the diameter of the nanoparticles were $25 \mathrm{~nm}$ and the Films were uniform. The incident energy is $25 \mathrm{KeV}$ and to avoid over exposure the exposure dose was $265 \mu \mathrm{C} / \mathrm{cm}^{2}$.

From the scattering trajectories seen in figure 17, it shows that the incident electrons experience a number of collisions with the atoms in the PMMA molecule in its flight, as this process occurs; the electrons diverge away from the incident beam. Hence, as the incident electron travels through the PMMA resist then the number of collisions increases and therefore dramatically increases the proximity effect.

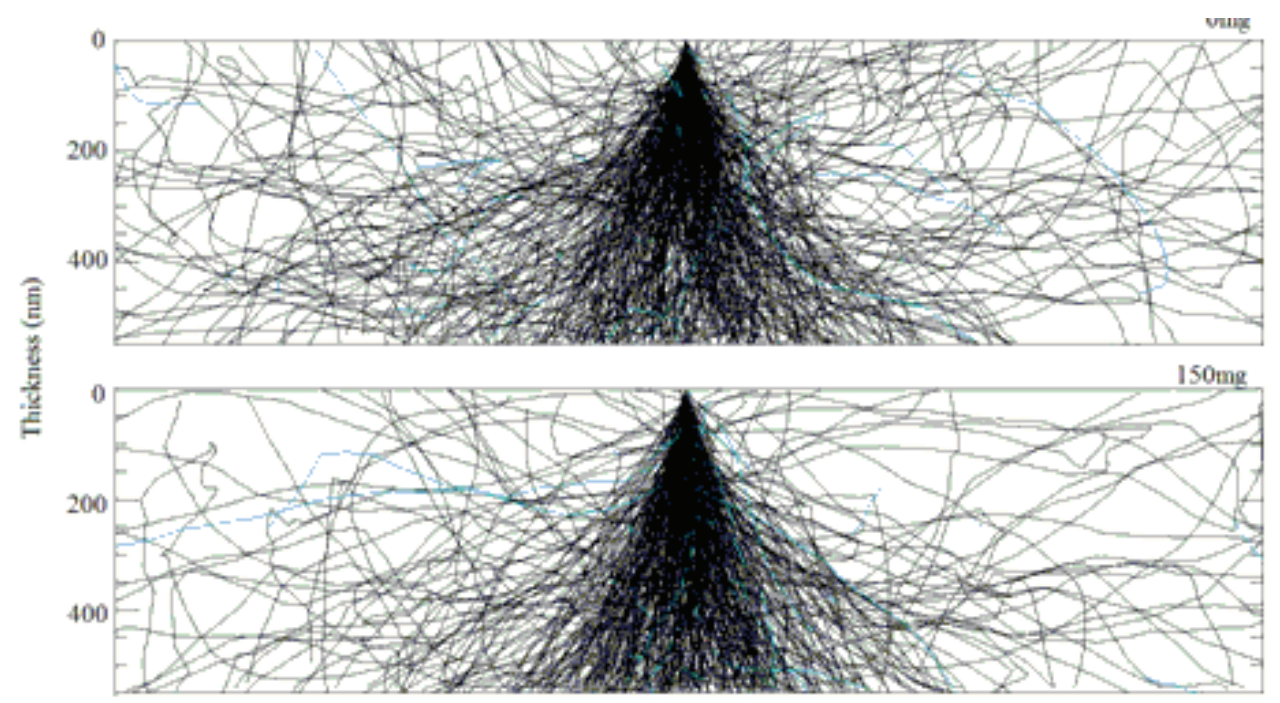

Fig. 17. Point electron distribution of standard PMMA and PMMA loaded with 150mg of $\mathrm{Al}_{2} \mathrm{O}_{3}$ nanoparticles. 
This was achieved when an incident electron collides with the surface of the resist, the Monte Carlo calculations for its trajectory start. As the electron penetrates through the resist, the Monte Carlo procedure was paused at every 50nm in depth (along $z$ axis). At this point the electron's $(x, y)$ coordinates were retrieved. The radial distance of the $n^{\text {th }}$ electron at depth $z$ was calculated using,

$$
r_{n}(z)=\sqrt{x^{2}+y^{2}} \quad \text { for } z=50,100,150 \ldots \mathrm{nm},
$$

this value is then stored and the procedure continued. This process is repeated for every incident electron, and all of the values of $r$ are stored. Once all of the electrons have entered the resist the values of $r_{n}$ are recalled for each depth and are averaged. If a total of $N$ electrons have penetrated the resist then the average radial distance at depth $z$ is given by,

$$
R(z)=\frac{\sum_{n=1}^{N} r_{n}(z)}{N} .
$$

Figure 18 demonstrates that when the electron spread of the primary electrons had cleared the resist, the average radial distances were approximately 382 and $112 \mathrm{~nm}$ for the unloaded PMMA and PMMA loaded with $150 \mathrm{mg}$ of $\mathrm{Al}_{2} \mathrm{O}_{3}$ nanoparticle, respectively.

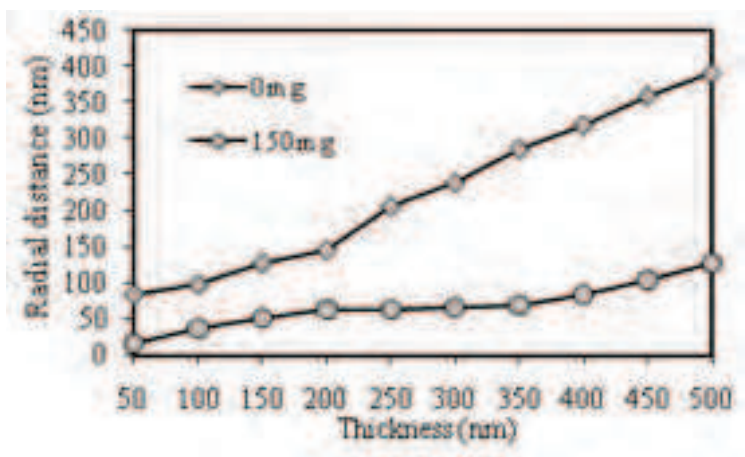

Fig. 18. Average radial distance of standard PMMA and PMMA loaded with 150mg of $\mathrm{Al}_{2} \mathrm{O}_{3}$ nanoparticles.

From figure 18, if the film thickness was reduced to 400nm of the thickness of the standard PMMA, the electron spread is considerably reduced. This demonstrates that thickness play a major role when exposing the resist to achieve the smallest nano structures.

This result shows that when the nanoparticle are introduced into the PMMA, the electrons incident on the nanocomposite resist experience a greater number of collisions with the atoms in its flight through the nanocomposite resist, hence, the mean free path was decreased. Therefore, the presence of the $\mathrm{Al}_{2} \mathrm{O}_{3}$ nanoparticles in the PMMA dramatically affects the mean free path and thus controlled the number of collisions that an incident electron encounters in its trajectory. This was due to the fact that the density of the $\mathrm{Al}_{2} \mathrm{O}_{3}$ nanoparticle was larger than the PMMA molecule.

In order to understand the role of secondary electrons in the 'proximity effect', the number of secondary electrons that are created per primary inserted and the distance that they travel 
through the resist was simulated by the Mont Carlo model. The number of secondary electrons created is shown in figure 19. From this characteristic, it was found that the number of secondary electrons created were considerably more than the number of the primary electrons incident on the nanocomposite resist surface. It can be seen that number of secondary electrons that were created was 2.0 (per primary electron) when the PMMA was unloaded. Comparing this to the PMMA that was loaded with 150mg of $\mathrm{Al}_{2} \mathrm{O}_{3}$ nanoparticles, the quantity of secondary electrons that were created was 1.6 (per primary electron). Thus, the presence of the $\mathrm{Al}_{2} \mathrm{O}_{3}$ nanoparticles in the nanocomposite resist film had the effect of quenching the secondary electrons.

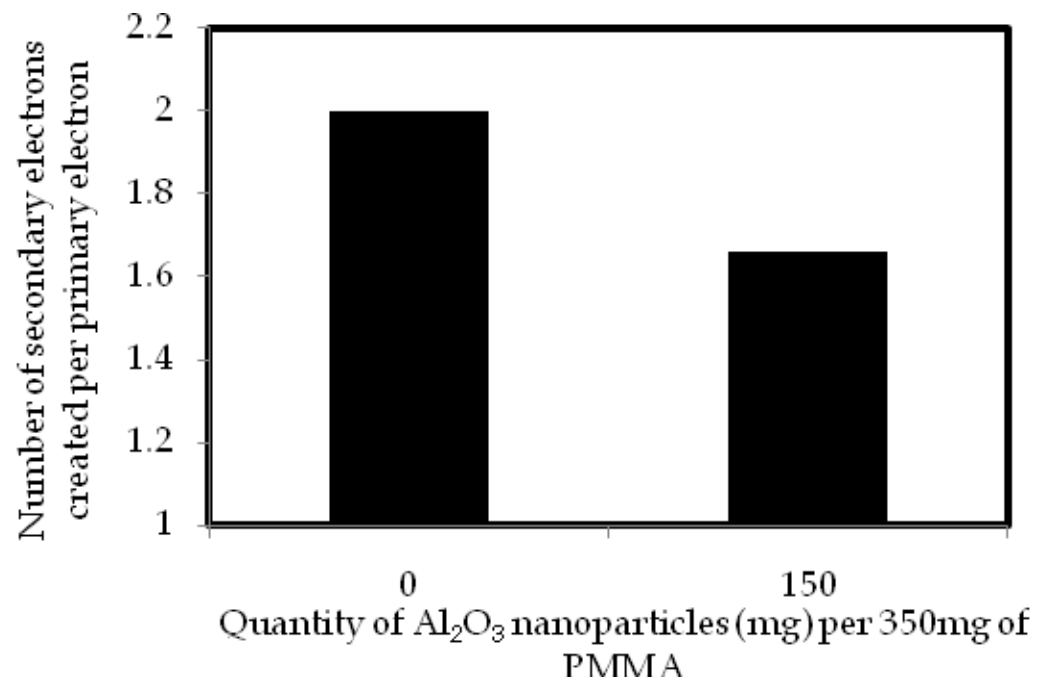

Fig. 19. Number of secondary electrons created per primary electron for a standard PMMA and PMMA based nanocomposite resist.

It was observed that the distance travelled by the secondary electrons decreases as the nanoparticle concentration was introduced and this is shown in figure 20. The secondary electrons travel further in standard PMMA when compared with PMMA based nanocomposite resist. This was due to the stopping power of the $\mathrm{Al}_{2} \mathrm{O}_{3}$ nanoparticles and is associated with the density of the $\mathrm{Al}_{2} \mathrm{O}_{3}$ nanoparticles. Note: the atomic numbers associated with the atoms within the nanoparticle are substantially larger than that of the PMMA polymer (Gonsalves et al 2001). The stopping power reduces the lateral distance and energy spread of the electrons travelling through the PMMA polymer.

When the PMMA was loaded with the $\mathrm{Al}_{2} \mathrm{O}_{3}$ nanoparticles they were able to confine the incident electrons. This was because the $\mathrm{Al}_{2} \mathrm{O}_{3}$ nanoparticles had a larger density than the PMMA molecule. This resulted in a stronger shielding of the atom which was provided by a larger charge. Therefore, an increased number of collisions took place due to an increasing density of the $\mathrm{Al}_{2} \mathrm{O}_{3}$ nanoparticles. Therefore, a higher aspect ratio can be achieved by loading the PMMA with a high density material and obtains a better resolution than resists like PMMA. These results agree with the work by A. Jeyakumar on Silica nanoparticles (Jeyakumar 2004). 


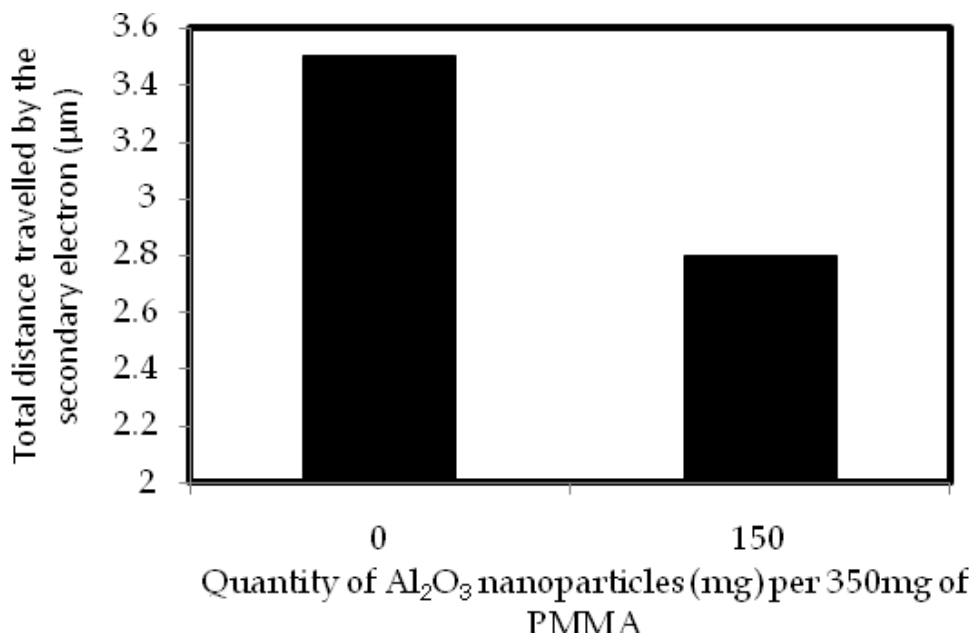

Fig. 20. Total distance travelled by the secondary electrons in a standard PMMA and PMMA loaded with $150 \mathrm{mg}$ of $\mathrm{Al}_{2} \mathrm{O}_{3}$ nanoparticles.

\section{Exposure of the nanocomposite resist to the electron beam}

To investigate the aspect ratio of developed features a series of $90 \mathrm{~nm}$ and $70 \mathrm{~nm}$ lines with spacings of $180 \mathrm{~nm}$ and $140 \mathrm{~nm}$ with a length of $20 \mu \mathrm{m}$ were exposed. The nanocomposite resist loaded with $150 \mathrm{mg}$ of $\mathrm{Al}_{2} \mathrm{O}_{3}$ nanoparticles and the standard PMMA were exposed with a dose of 265 and $200 \mu \mathrm{C} / \mathrm{cm}^{2}$ respectively.

Figures 21 and 22 show SEM images that feature nano structures consisting of $90 \mathrm{~nm}$ and $70 \mathrm{~nm}$ trenches. Figure 21a shows features that consisted of lines and spaces (trenches) in the PMMA 950K 7\% sample loaded with 150mg of nanoparticles. The lines had a width of $185 \mathrm{~nm}$ and the spacing between each of the lines was $91 \mathrm{~nm}$; as the resist thickness was $562 \mathrm{~nm}$ this gives a high aspect ratio of approximately 6.2:1. The SEM image in Figure 21b shows the unloaded PMMA 950K 7\% resist; the aspect ratio is 4.4:1, with line widths of $185 \mathrm{~nm}$ and spacings of $91 \mathrm{~nm}$.

We have been able to produce $90 \mathrm{~nm}$ trenches in a thicker resist because the $\mathrm{Al}_{2} \mathrm{O}_{3}$ nanoparticles have contributed to reducing the proximity effect. Also the mechanical properties of the PMMA have been improved by the addition of $\mathrm{Al}_{2} \mathrm{O}_{3}$ nanoparticles by providing an internal mechanism that bonds the PMMA resist together. Figure 22a shows the lines fabricated in PMMA 950K 7\% loaded with 150mg of $\mathrm{Al}_{2} \mathrm{O}_{3}$ nanoparticles. Each line consisted of feature sizes of $70 \mathrm{~nm}$. However, much of the periodic spacing has disappeared, suggesting that the resist has collapsed. Both the primary and secondary electrons have undercut the nanocomposite resist from the silicon surface and consequently the nanocomposite resist has toppled over. The resist was clearly compromised by the proximity effect. From Figure 22, it can be seen clearly that the $\mathrm{Al}_{2} \mathrm{O}_{3}$ nanoparticles have bound the PMMA polymer together, to make the material more rigid, as the resist has remained intact. In the sample of the standard PMMA 950k 7\% (Figure 22b), there are no lines, they have completely collapsed. This is due to the fact that the nanocomposite resist is too thick to control the primary and secondary electrons from transmitting laterally. 


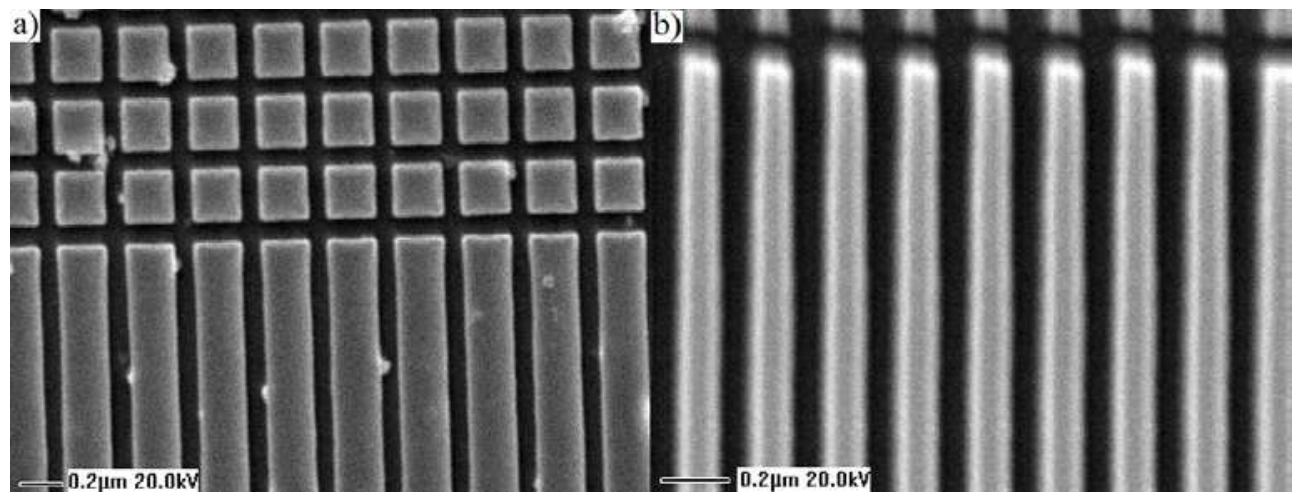

Fig. 21. PMMA 950K $7 \%$ nanocomposite resist exposed at $265 \mu \mathrm{C} / \mathrm{cm}^{2}$, a) loaded with $150 \mathrm{mg}$ of $\mathrm{Al}_{2} \mathrm{O}_{3}$ nanoparticles, b) Standard PMMA 950K 7\%.

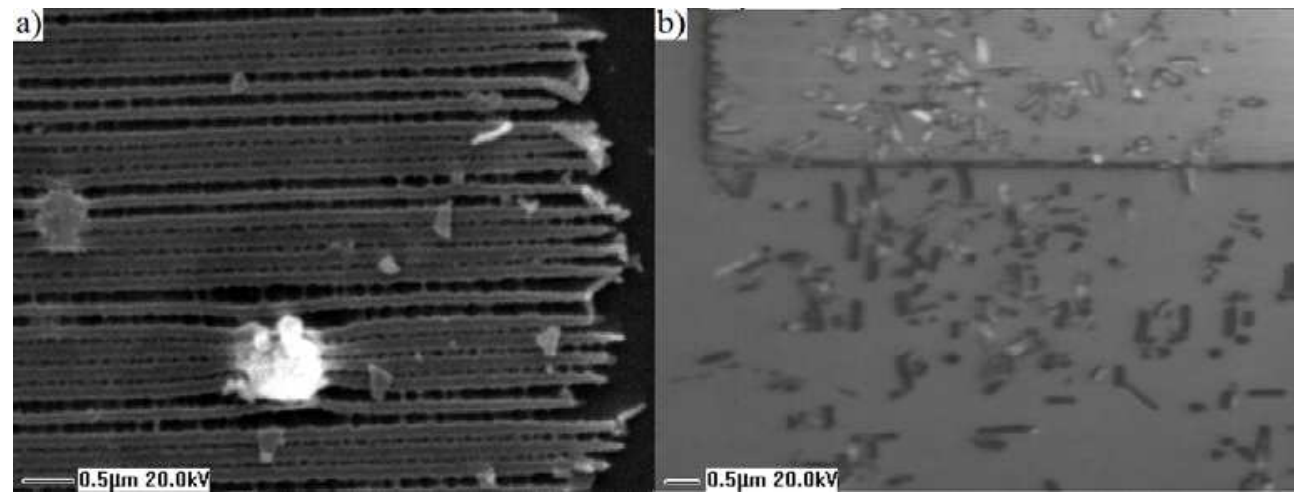

Fig. 22. SEM image of collapsed features in PMMA 950K 7\% nanocomposite resist exposed at $265 \mu \mathrm{C} / \mathrm{cm}^{2}$, a) loaded with $150 \mathrm{mg}$ of $\mathrm{Al}_{2} \mathrm{O}_{3}$ nanoparticles, b) Standard PMMA 950K 7\%.

From the SEM images in figures 21a and 22a it can be seen that the Line Edge Roughness (LER) of the resultant features has degraded due to the fact that the $\mathrm{Al}_{2} \mathrm{O}_{3}$ nanoparticles have aggregated together (Lewis et al 2010).

It is evident that as the quantity of the nanoparticles was increased, the LER is also increased. The LER needs to be as small as possible as to not compromise the pattern. In this case, therefore, reducing the concentration of $\mathrm{Al}_{2} \mathrm{O}_{3}$ nanoparticles in PMMA 950K 7\% will reduce the LER.

\section{Summary}

A novel electron beam resist has been demonstrated by incorporating $\mathrm{Al}_{2} \mathrm{O}_{3}$ nanoparticles with a diameter of 15 - 25nm into the PMMA polymer matrix. Oxide nanoparticles were introduced into the polymeric matrix by adding the oxide nanoparticles directly into the PMMA matrix, the PMMA became inhomogeneous. This was indicated by an increase in surface rms roughness measured (via an AFM). This was found to be $402 \mathrm{~nm}$ produced by $\mathrm{Al}_{2} \mathrm{O}_{3}$ nanoparticles. This was due to poor particle dispersion as a result of the inter-particle 
attraction between each nanoparticle caused by the depletion effect. With the surface roughness the resultant pattern developed in the nanocomposite resist would have had a poor edge definition.

Therefore, to improve the homogeneous surface quality, the oxide nanoparticles were suspended in Methanol and Toluene. This was measured by using the zeta potential parameter. It was found that the Methanol suspended the oxide nanoparticles successfully. The zeta potential value was $39.2 \mathrm{mV}$; where the oxide nanoparticle suspension was stable. This method improved the surface roughness of PMMA when the $\mathrm{Al}_{2} \mathrm{O}_{3}$ was suspended in Methanol. The PMMA with $200 \mathrm{mg}$ of $\mathrm{Al}_{2} \mathrm{O}_{3}$ nanoparticles embedded within it had an rms roughness of $63 \mathrm{~nm}$. The improvement here was a factor of 6.34 .

The increased number density of $\mathrm{Al}_{2} \mathrm{O}_{3}$ nanoparticles in the PMMA required an increase in the clearing dose. The presence of the nanoparticles had a quenching effect on the electrons within the resist responsible for 'exposing' the resist. Consequently, this affected the outcome of the developed features, to the extent that in some cases, the features produced were completely deformed. In some instances, nanoparticle clustering affected the quality of the pattern obtained. It was found that as the quantity of the nanoparticles was increased, the line edge roughness (LER) also increased. LER needs to be as small as possible as to not compromise the pattern.

It was found that the $\mathrm{Al}_{2} \mathrm{O}_{3}$ nanoparticles had prevented the lines from collapsing by blocking the arbitrary scattering secondary electrons from transmitting laterally throughout the nanocomposite resist. Thus, the proximity effect was reduced.

It was found in all samples that, when the line widths were reduced beyond 70nm they had collapsed. However, the lines in the nanocomposite resist had toppled over and thus not completely destroyed. It is suspected that the $\mathrm{Al}_{2} \mathrm{O}_{3}$ nanoparticles have affected the mechanical properties of the PMMA by causing the molecular chain of the polymer to bond with the $\mathrm{Al}_{2} \mathrm{O}_{3}$ nanoparticles. All the lines are completely destroyed in the unloaded samples of PMMA 950K 7\%.

\section{References}

R. L. Dean, H. Y. Lem, C. A. Sauer, H. Chang, (1994). PBS resist profile studies for sub micron mask lithography. Proc. SPIE, vol. 2322., 102.

B. Erdem, E. D. Sudol, V. L. Dimonie, M. S. El - Aasser, (2000). Encapsulation of inorganic particles via miniemulsion polymerization. II. Preparation and characterization of sturene minienulsion droplets containing $\mathrm{TiO}_{2}$ particles. J. Polym. Sci. Part. A: Polym. Chem (38) page number $4431-40$.

K. E. Gonsalves, L. Merhari, H. Wu, Y. Hu, (2001). Organic - inorganic nanocomposite: unique resists for nanolithography. Advanced Materials, Vol 13, No 13.

T. Ishii, H. Nozawa, T. Tamamura, (1997). A nano - composite resist system: a new approach to nanometer pattern fabrication. Microelectronic Engineering, vol 35., no 1., page numbers $113-116$.

T. Ishii, H. Nozawa, T. Tamamura, (1997). C60 incorporated nanocomposite resist system. J. Photopolymer. Sci. Technol, vol 10., no 4., page numbers 651 - 656. 
T. Ishii, T. Tamamura, K. Shigehara, (2000). Fullerene - derivative nanocomposite resist for nanometer pattern fabrication. Jpn. J. Appl. Phys. Vol., 39 page numbers L1068 L1070.

T. Ishii, Y. Murate, K. Shigehara, (2001).'Contrast enhancement of ZEP520 resist by fullerene - derivate incorporation. Jpn. J. Appl. Phys Vol., 40 page numbers L478 - L480.

P, Judeinstein, C. Sanchez, (1996). Hybrid organic - inorganic materials: a land of multidisciplinarity. J. Mater. Chem (6) page number $511-25$.

S. Lewis, V. Haynes, R. Wheeler-Jones, J. Sly, R.M. Perks \& L. Piccirillo, (2010). Surface characterization of poly(methylmethacrylate) based nanocomposite thin films containing $\mathrm{Al}_{2} \mathrm{O}_{3}$ and $\mathrm{TiO}_{2}$ nanoparticle. Thin Solid Films Vol., 518, No., 10, page numbers 2683-2687.

S. R. Lu, H. L. Zhang, C. X. Zhao, X. Y. Wang, (2005). Studies on the properties of a new hybrid materials containing chain extended area and $\mathrm{SiO}_{2}-\mathrm{TiO}_{2}$ particles. Polymer (46) page number $10484-92$.

L. Merhari, K. E. Gonsalves, Y. Hu, W. He, W. -S. Huang, m. Angelopoulos, W. H. Bruenger, C. Dzionk \& M. Torker, (2002). Nanocomposite resist systems for next generation lithography. Microelectronic Engineering Vol., 63, page numbers 391 - 403.

R. A. Potyrailo (2006). Polymeric sensor materials: toward an alliance of combinatorial and rational design tools? Angew. Chem. Int. Edit. (45), page numbers 702 - 23.

A. Sidorenko, S. Minko, G. Gafijchuk, S. Voronov, (1999). Radical polymerization initiated from a solid substrate. 3. grafting from the surface of an ultrafine powder. Macromolecules (32) page number 4530 - 43.

A. H. Yuwono, B. Liu, J. Xue, J. Wang, H. I. Elim, W. Ji et al, (2005). Controlling the crystallinity and nonlinear optical properties of transparent $\mathrm{TiO}_{2}-\mathrm{PMMA}$ nanohybrids. J. Mater. Chem (14) page number $2978-87$. 


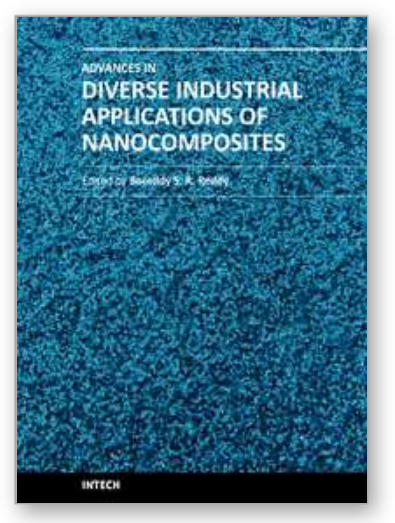

\author{
Advances in Diverse Industrial Applications of Nanocomposites \\ Edited by Dr. Boreddy Reddy
}

ISBN 978-953-307-202-9

Hard cover, 550 pages

Publisher InTech

Published online 22, March, 2011

Published in print edition March, 2011

Nanocomposites are attractive to researchers both from practical and theoretical point of view because of combination of special properties. Many efforts have been made in the last two decades using novel nanotechnology and nanoscience knowledge in order to get nanomaterials with determined functionality. This book focuses on polymer nanocomposites and their possible divergent applications. There has been enormous interest in the commercialization of nanocomposites for a variety of applications, and a number of these applications can already be found in industry. This book comprehensively deals with the divergent applications of nanocomposites comprising of 22 chapters.

\title{
How to reference
}

In order to correctly reference this scholarly work, feel free to copy and paste the following:

Scott Lewis and Lucio Piccirillo (2011). Influence of Nanocomposite Materials for Next Generation Nano Lithography, Advances in Diverse Industrial Applications of Nanocomposites, Dr. Boreddy Reddy (Ed.), ISBN: 978-953-307-202-9, InTech, Available from: http://www.intechopen.com/books/advances-in-diverse-industrialapplications-of-nanocomposites/influence-of-nanocomposite-materials-for-next-generation-nano-lithography

\section{INTECH}

open science | open minds

\section{InTech Europe}

University Campus STeP Ri

Slavka Krautzeka 83/A

51000 Rijeka, Croatia

Phone: +385 (51) 770447

Fax: +385 (51) 686166

www.intechopen.com

\section{InTech China}

Unit 405, Office Block, Hotel Equatorial Shanghai

No.65, Yan An Road (West), Shanghai, 200040, China

中国上海市延安西路65号上海国际贵都大饭店办公楼 405 单元

Phone: +86-21-62489820

Fax: +86-21-62489821 
(C) 2011 The Author(s). Licensee IntechOpen. This chapter is distributed under the terms of the Creative Commons Attribution-NonCommercialShareAlike-3.0 License, which permits use, distribution and reproduction for non-commercial purposes, provided the original is properly cited and derivative works building on this content are distributed under the same license. 